\title{
(C) OPEN ACCESS \\ What do Canadians think of advanced care planning? Findings from an online opinion poll
}

\author{
Ana A Teixeira, ${ }^{1}$ Louise Hanvey, ${ }^{2}$ Carolyn Tayler $^{3}$ Doris Barwich, ${ }^{3,4}$ \\ Sharon Baxter, ${ }^{2}$ Daren K Heyland, ${ }^{1,5,6}$, On behalf of the Canadian \\ Researchers at the End of Life Network (CARENET)
}

\begin{abstract}
- Additional material is published online only. To view please visit the journal online (http://dx.doi.org/10.1136/ bmjspcare-2013-000473).

For numbered affiliations see end of article.
\end{abstract}

\section{Correspondence to}

Dr Daren K Heyland, Department of Medicine, Queen's University, Kingston General Hospital, Angada 4, 76 Stuart Street, Kingston, Ontario, Canada K7L 2V7

dkh2@queensu.ca

Received 22 February 2013 Revised 6 September 2013 Accepted 9 September 2013 Published Online First 4 October 2013

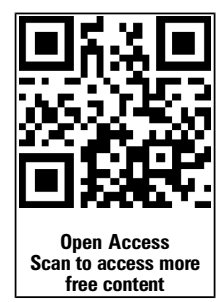

CrossMark

To cite: Teixeira $A A$,

Hanvey L, Tayler C, et al. BMJ Supportive \& Palliative Care 2015:5:40-47.

\section{ABSTRACT}

Background Advance care planning (ACP) has the potential to increase patient-centred care, reduce caregiver burden, and reduce healthcare costs at the end of life. Current levels of public participation in ACP activities are unknown. The purpose of this study was to determine the level of engagement of average Canadians in ACP activities.

Methods Data come from an on-line opinion poll of a national sample of respondents who were asked five questions on ACP activities along with their sociodemographic characteristics.

Results Respondents were from all provinces of Canada, 52\% were women, and 33\% were between 45 years and 54 years of age. Of 1021 national sample respondents, $16 \%$ were aware of the term, ACP (95\% Cl 13\% to 18\%), 52\% had discussions with their family or friends $(95 \%$ $\mathrm{Cl} 49 \%$ to $55 \%$ ), and $10 \%$ had discussions with healthcare providers (95\% Cl $8 \%$ to $12 \%$ ).

Overall, $20 \%$ (95\% Cl $18 \%$ to $22 \%$ ) of respondents had a written ACP and 47\% (95\% $\mathrm{Cl} 44 \%$ to $50 \%$ ) had designated a substitute decision maker. Being older was associated with significantly more engagement in ACP activities and there were significant differences in $\mathrm{ACP}$ engagement across Canada.

Conclusions Although only a small proportion of Canadians are aware of the formal term, ACP, a higher percentage of Canadians are actually engaged in ACP, through either having discussions or making decisions about end-of-life care. Older citizens are more likely to be engaged in ACP and there are geographic differences in the level of ACP engagement across Canada.

\section{INTRODUCTION}

Advance care planning (ACP) is defined as a process whereby a person considers options about future healthcare decisions and identifies and communicates their wishes. ACP is a process, not an event. It encourages dialogue among a patient, their family, friends, substitute decision makers and the healthcare team. Consequently, it promotes patient-centred care with appropriate supports and quality care. The essential tasks of ACP at the individual and system level involve processes that support: asking the person about their personal values and wishes for care at the end of life (EOL); ensuring that the person and family understand disease progression and prognosis; discussions of treatment options-risks, benefits and expected outcomes; deciding on future care or goals of care if the person is unable to engage in future decision making; documenting discussions and decisions in a way that is accessible in various settings of care; and honouring personal wishes and ensuring that care is consistent with preferences. ${ }^{1-4}$

There is a generalised belief that ACP is uniquely intended for frail or aging populations. However, awareness about and use of ACP could benefit all adults. Although older adults are more likely to face sudden incapacity or death, there is a need to generalise discussions and reflections about death and dying to the broader population. Such discussions would potentially encourage younger adults to manage their own EOL care in the event of a medical emergency and prepare them to discuss EOL matters with their parents or close relatives. ${ }^{5}$ Extant research has shown that ACP activities are important because (A) quality at the end of life improves for the individual when an advance plan exists; and (B) when communication about ACP 
or advance directives is efficient, the burden of care placed on the individual's family and caregivers decreases. ${ }^{6-8}$

Current levels of public engagement in ACP activities are unknown. Past research suggests that only a small percentage of the population is involved in ACP activities. ${ }^{9-11}$ Yet, ACP is not homogeneously distributed in populations. Sociodemographic factors such as age, gender, ethnicity, income, religion and education play an important role in individuals' awareness, communication and decision making about ACP. $^{12}{ }^{13}$ Moreover, some ACP interventions have successfully increased levels of public engagement in ACP. ${ }^{14}{ }^{15}$ In Canada, the Fraser Health Authority (FHA) in British Columbia $(\mathrm{BC})$ has been implementing region-wide ACP engagement initiatives since 2004 including public awareness and education. ${ }^{5}$ This study constitutes one of the first comparative assessments of ACP usage in the FHA and the rest of Canada.

The objective of the present study was to evaluate Canadians' current knowledge on ACP. First, we describe ACP behaviour among sample respondents. We then examine how sociodemographic patterns influence ACP in Canada, and whether these patterns differ according to components of ACP: awareness, communication and decision making. Finally, we compare ACP engagement in the FHA with the rest of Canada, and with the remaining $\mathrm{BC}$ province.

\section{METHODS}

\section{Sample and survey}

In March 2012, an opinion poll surveyed the Canadian population on knowledge and attitudes towards ACP. The poll included a national sample of 1021 Canadians and an additional oversample of 502 respondents residing in the FHA, BC (total $n=1523$ ). Respondents formed the Ipsos Reid eNation Canada Omnibus survey and were randomly selected from the company's $170000+$ member national online panel (i-Say) Ipsos Consumer Panel database. ${ }^{16} 17$ The online panel was recruited and maintained using double and triple opt-in screening processes. Respondents were individuals living in Canada, 18 years of age or older, and recruited from all provinces of Canada. There were no respondents from the Northwest Territories, Nunavut and Yukon. The opinion poll was commissioned by CARENET (Canadian Researchers at the End of Life Network, http://www.thecarenet.ca), the FHA, the Canadian Hospice and Palliative Care Association, and the Speak Up Campaign and was conducted by Ipsos Reid. Survey questions were designed by the study team (DH, LH, SB, CT and DB) and the ACP question set was part of a short online survey which took approximately $15-20 \mathrm{~min}$ to complete. The ACP section took approximately $5 \mathrm{~min}$ to complete, but respondents could take longer to complete the survey.

\section{Measures}

Advance care planning outcomes

Five ACP questions were asked. First, participants were asked (Q1) whether they had ever heard of the term 'ACP'. Respondents were then provided with the following description of ACP: 'Advance care plans are verbal or written instructions that make your wishes known about the kind of healthcare you want (or do not want) if you become very ill or injured and are unable to speak for yourself. These are sometimes also called "living wills".' Participants were then asked (Q2) whether they ever had a discussion with a family or friend or a (Q3) healthcare provider regarding healthcare treatments' preferences in the event that they would become too ill or too injured to speak for themselves; (Q4) whether respondents have written an advance care plan, and (Q5) if they had designated a person to be their healthcare decision maker in the event of incapacity. ${ }^{16}$ The questions were designed to gather information on three dimensions of ACP: awareness (Q1), communication (Q2 and Q3); and decision making (Q4 and Q5). To have information on comprehensive ACP behaviour, we created a variable that measured the number of times a respondent answered 'yes' to each ACP question. This variable could assume a value of ' 0 ' if a respondent answered 'no' to all five questions or it could have a value of ' 5 ' if respondent engaged in all five ACP behaviours.

Independent variables

Six sociodemographic and economic variables were examined. Gender, whether respondents were born in Canada or not, and whether children (ie, 'kids') resided in the household, were indicator variables. Age, educational attainment, and household income were modelled as ordinal variables. Age had six categories (18-24 years old, 25-34, 35-44,45-54, 55-64, 65 and plus), educational attainment had four categories (ie, less than high school, high school, postsecondary education, and university degree), and household income had five categories (less than $\$ 25 \mathrm{~K}, \$ 25 \mathrm{~K}-<\$ 50 \mathrm{~K}, \$ 50 \mathrm{~K}-<\$ 100 \mathrm{~K}$, $\$ 100 \mathrm{~K}-<\$ 150 \mathrm{~K}$ and more than $\$ 150 \mathrm{~K}(\mathrm{CAD} \$))$. To test whether the association of age, education and income with ACP was nonlinear, we first modelled these variables as dummy variables. No nonlinear effects were observed and the variables were modelled in ordinal form. We used a variable indicating whether respondents resided in the FHA or not for the analysis of the ACP intervention in the FHA.

\section{Comparative analysis between the FHA's ACP intervention and the rest of Canada}

A comparison between the FHA sample and the rest of the Canadian sample was done to understand whether there were significant differences in the level of ACP engagement between a region with an emphasis on ACP engagement initiatives compared with regions without interventions. The FHA serves a 
population of 1.5 million individuals and has been implementing an ACP engagement programme called 'Let's Talk', since 2004. This programme promotes the education of the public and healthcare professionals (HCP), the engagement of community leaders and organisations, and the development of tools and resources to support integration of ACP into the care received. Some of these resources included a provincial toll-free telephone line, a website and a number of documents, most notably an ACP workbook (My Voice Workbook) that could be used by patients and the public to help them develop an advance care plan, or approach a HCP around healthcare decision making at the EOL (http://www.fraserhealth.ca/your_ care/advance-care-planning/). ${ }^{5}$

\section{Analysis}

We first report descriptive information on the six ACP components for the national sample. Second, six separate logistic regression models were estimated for each ACP outcome with adjustment for sociodemographic variables. Model 1 examined ACP awareness, Models 2 and 3 analysed ACP communication, Models 4 and 5 focused on ACP decision making, and Model 6 examined an aggregated ACP outcome. Third, we used Pearson $\chi^{2}$ tests and two sample $t$ tests with equal variance to compare the FHA $(n=532)$ with the rest of Canada $(n=991)$ on the six ACP outcomes, and the FHA with the rest of BC. To model the effect of FHA on ACP outcomes while controlling for sociodemographic characteristics, we included the FHA indicator variable in the logistic regression models. To assess whether sociodemographic characteristics differed between the FHA oversample and the rest of Canada, we estimated Pearson $\chi^{2}$ statistics. Stata/MP V.11.0 was used for statistical analyses.

\section{RESULTS}

\section{Sociodemographic characteristics associated with ACP behaviour}

Table 1 provides sociodemographic information on the national sample and the FHA oversample. Compared with the rest of Canada, the FHA had a higher percentage of older population, higher numbers of university graduates, higher household incomes, and a greater proportion of households with children and individuals born outside Canada.

The distribution of the six ACP outcomes in the national sample can be seen in the first column of table 2 . In the national sample, $16 \%$ of respondents (95\% CI $13 \%$ to $18 \%$ ) were aware of the term 'ACP', $52 \%$ of respondents (95\% CI $49 \%$ to $55 \%$ ) acknowledged having had discussions with their family or friends, and $10 \%$ (95\% CI $8 \%$ to $12 \%)$ had discussions with HCPs. Regarding ACP decision making, $20 \%$ of respondents (95\% CI $18 \%$ to $22 \%$ ) had a written ACP and 47\% of respondents (95\% CI 44\% to $50 \%$ ) had a substitute decision maker. Regarding the aggregate measure of ACP, the national sample had a mean value of 1.45 (95\% CI 1.36 to 1.53 ).

Table 3 provides the results from the multivariable logistic regression analyses. Age was the only variable positively associated with the five ACP outcomes. Model 1 showed that individuals who were older, had higher educational levels, or did not live with children in the household had higher odds of knowing the term ACP. Model 2 showed that respondents who were women, older, or with higher levels of income were more likely to discuss ACP matters with family and friends. Model 3 found that the likelihood of having discussions with HCPs increased for older respondents and for those not born in Canada, but decreased for individuals of higher income and those living with children. Model 4 indicated that older individuals and those with higher educational levels were more likely to have a written ACP. Model 5 showed that older individuals and those with higher incomes were more likely to have designated a substitute decision maker. Model 6 indicated that being a woman, being older, and having a higher income makes respondents more likely to be engaged in more ACP activities. An online supplementary table S1 is provided showing the unadjusted OR for all models.

\section{Comparative usage of ACP in the FHA, the rest of Canada and BC}

Table 2 shows results comparing different ACP components between FHA and the rest of Canada. The first set of comparisons showed significant differences for three ACP outcomes: FHA registers higher levels of ACP awareness than the rest of Canada ( $20 \%$ vs $15 \%, \mathrm{p}=0.025)$, and higher rates of ACP discussions with family and friends $(59 \%$ vs $51 \%, \mathrm{p}=0.004)$. These differences did not persist after adjustment for sociodemographic variables (table 3). Respondents from the FHA had lower rates of written ACPs than other Canadians $(15 \%$ vs $20 \%, \mathrm{p}=0.018)$, and this difference persisted after controlling for sociodemographic variables (table 3). Model 5 showed that FHA residents were less likely to have a substitute decision maker than other Canadians. Comparisons between FHA and the rest of BC in table 2 showed no significant differences.

\section{DISCUSSION}

\section{ACP behaviour in Canada}

The Ipsos Reid poll demonstrated that, overall, Canadians had little recognition of the term 'ACP' and yet, a higher percentage of respondents actually practiced ACP in their lives, either by having discussions, or by making decisions about EOL care. However, knowledge about ACP terms may not be indicative of participation in key activities. For instance, a Pew Research Center study found that $95 \%$ of the US population had heard of living wills in 2005, but only $29 \%$ had living wills. ${ }^{11}$ 
Table 1 Sociodemographic description of the national sample $(n=1021)$, the rest of Canada $(n=991)$ and the Fraser Health Authority (FHA) samples $(n=532)^{*}$

\begin{tabular}{|c|c|c|c|c|c|}
\hline Sociodemographic variables & Categories & $\begin{array}{l}\text { National sample } \\
(n=1021)\end{array}$ & $\begin{array}{l}\text { Rest of Canada } \\
(n=991)\end{array}$ & $\begin{array}{l}\text { FHA } \\
(n=532)\end{array}$ & p Valuet \\
\hline Gender (\%) & $\begin{array}{l}\text { Male } \\
\text { Female }\end{array}$ & $\begin{array}{l}487(48) \\
534(52)\end{array}$ & $\begin{array}{l}472(48) \\
519(52)\end{array}$ & $\begin{array}{l}275(52) \\
257(48)\end{array}$ & 0.130 \\
\hline Age $(\%)$ & $\begin{array}{l}18-24 \\
25-34 \\
35-44 \\
45-54 \\
55-64 \\
65+\end{array}$ & $\begin{array}{c}42(4) \\
189(19) \\
47(5) \\
339(33) \\
187(18) \\
217(21)\end{array}$ & $\begin{array}{c}42(4) \\
184(19) \\
45(5) \\
330(33) \\
184(19) \\
206(21)\end{array}$ & $\begin{array}{c}7(1) \\
53(10) \\
69(13) \\
93(17) \\
140(26) \\
170(32)\end{array}$ & $<0.001$ \\
\hline Education (\%) & $\begin{array}{l}<\text { High school } \\
\text { High school } \\
\text { Postsec } \\
\text { Univ grad }\end{array}$ & $\begin{array}{c}81(8) \\
330(32) \\
480(47) \\
130(13)\end{array}$ & $\begin{array}{c}79(8) \\
317(32) \\
468(47) \\
127(13)\end{array}$ & $\begin{array}{c}33(6) \\
110(21) \\
231(43) \\
158(30)\end{array}$ & $<0.001$ \\
\hline Household income, US\$ (\%) & $\begin{array}{l}<\$ 25 K \\
\$ 25 K-<\$ 50 K \\
\$ 50 K-<\$ 100 K \\
\$ 100 K-<\$ 150 K \\
\$ 150 K+\end{array}$ & $\begin{array}{c}172(17) \\
245(24) \\
434(43) \\
146(14) \\
24(2)\end{array}$ & $\begin{array}{c}167(17) \\
235(24) \\
423(43) \\
143(14) \\
23(2)\end{array}$ & $\begin{array}{c}64(12) \\
124(23) \\
193(36) \\
115(22) \\
36(7)\end{array}$ & $<0.001$ \\
\hline Region (\%) & $\begin{array}{l}\text { BC } \\
\text { AB } \\
\text { SK/MB } \\
\text { Ontario } \\
\text { Quebec } \\
\text { Atlantic } \\
\text { Don't know }\end{array}$ & $\begin{array}{c}189(18) \\
129(13) \\
77(7) \\
326(32) \\
231(23) \\
68(7) \\
1(0)\end{array}$ & $\begin{array}{c}159(16) \\
129(13) \\
77(8) \\
326(33) \\
231(23) \\
68(7) \\
1(0)\end{array}$ & $\begin{array}{c}532(100) \\
- \\
- \\
- \\
- \\
- \\
-\end{array}$ & $<0.001$ \\
\hline Has 'kids' in household (\%) & & $111(11)$ & $110(11)$ & $106(20)$ & $<0.001$ \\
\hline Not born in Canada (\%) & & $104(11)$ & $101(10)$ & $106(20)$ & $<0.001$ \\
\hline
\end{tabular}

*The national sample included 30 respondents from the FHA; the FHA sample included 502 oversample respondents and the 30 national sample respondents from the FHA; and the rest of Canada sample comprises the national sample respondents minus the 30 respondents from the FHA. tp Value reflects the extent to which FHA and rest of Canada significantly differ from each other (Pearson $\chi^{2}$ test).

One of the study's most important findings concerns communication around ACP. Canadians in our sample tended to talk more with their family and friends about ACP than with their own doctors or other HCPs. Similar results have been shown in other studies. A recent Canadian study of current ACP practices in elderly hospitalised patients at high risk of dying found that more than $75 \%$ of participants had thought about the care they would want in the final stages, and more than $90 \%$ had discussed their preferences with other family members. However, less than $30 \%$ had discussed their preferences for EOL care with doctors. ${ }^{1}$ An Ipsos Reid study conducted in 2004 reported that $44 \%$ of Canadians had discussions with family members about ACP, and only $9 \%$ had discussions with their doctor. ${ }^{10}$ Our study shows that when

Table 2 ACP usage in the national sample, and comparisons between FHA with the rest of Canada and FHA with the rest of BC

\begin{tabular}{|c|c|c|c|c|c|c|c|}
\hline \multirow[b]{2}{*}{ ACP outcomes } & \multirow{2}{*}{$\begin{array}{l}\text { National } \\
\text { sample } \\
(n=1021)\end{array}$} & \multicolumn{3}{|c|}{ FHA vs Rest of Canada } & \multicolumn{3}{|c|}{ FHA vs Rest of BC } \\
\hline & & $\begin{array}{l}\text { FHA } \\
(n=532)\end{array}$ & $\begin{array}{l}\text { Rest of Canada } \\
(\mathrm{n}=991)\end{array}$ & p Value* & $\begin{array}{l}\text { FHA } \\
(n=532)\end{array}$ & $\begin{array}{l}\text { Rest of } B C \\
(n=159)\end{array}$ & p Value* \\
\hline Knows the term ACP (\%) & $160(16)$ & $108(20.3)$ & $156(15.7)$ & 0.025 & $108(20.3)$ & $25(15.7)$ & 0.199 \\
\hline $\begin{array}{l}\text { ACP discussions with family/friends } \\
(\%)\end{array}$ & $530(52)$ & $316(59.4)$ & $512(51.7)$ & 0.004 & $316(59.4)$ & $87(54.7)$ & 0.293 \\
\hline $\begin{array}{l}\text { ACP discussions with healthcare } \\
\text { professionals (\%) }\end{array}$ & $105(10)$ & $66(12.4)$ & $102(10.3)$ & 0.209 & $66(12.4)$ & $23(14.5)$ & 0.496 \\
\hline Has an ACP written down (\%) & $204(20)$ & $82(15.4)$ & $202(20.4)$ & 0.018 & $82(15.4)$ & $21(13.2)$ & 0.493 \\
\hline Has substitute decision maker (\%) & $479(47)$ & $242(45.5)$ & $467(47 \%)$ & 0.542 & $242(45.5)$ & $70(44)$ & 0.745 \\
\hline $\begin{array}{l}\text { Aggregate } A C P \text { outcomes } \\
\text { (mean values) }\end{array}$ & $\begin{array}{l}1021 \\
1.45\end{array}$ & $\begin{array}{l}532 \\
1.53\end{array}$ & $\begin{array}{l}991 \\
1.45\end{array}$ & 0.29 & $\begin{array}{r}532 \\
1.53\end{array}$ & $\begin{array}{l}159 \\
1.42\end{array}$ & 0.37 \\
\hline
\end{tabular}

Bold text indicates that the coefficient is significant.

${ }^{*} p$ Values reflect the extent to which FHA and Rest of Canada and FHA and Rest of BC are different from each other (Pearson $\chi^{2}$ test for binary ACP outcomes and two sample t test with equal variance for aggregate ACP outcome).

ACP, advance care planning; FHA, Fraser Health Authority. 
Table 3 Influence of selected sociodemographic variables on advance care planning outcomes

\begin{tabular}{|c|c|c|c|c|}
\hline & OR & $\mathrm{p}>|\mathrm{z}|$ & \multicolumn{2}{|c|}{$(95 \% \mathrm{Cl})$} \\
\hline \multicolumn{5}{|l|}{ Model 1: Has heard of ACP } \\
\hline Female & 1.117 & 0.423 & 0.852 & 1.465 \\
\hline Age (6 categories) & 1.178 & 0.002 & 1.062 & 1.306 \\
\hline Education (4 categories) & 1.310 & 0.002 & 0.102 & 1.557 \\
\hline Income (5 categories) & 1.027 & 0.688 & 0.901 & 1.172 \\
\hline Has 'kids' in household & 0.537 & 0.014 & 0.326 & 0.884 \\
\hline Not born in Canada & 0.928 & 0.712 & 0.626 & 1.376 \\
\hline Fraser Health Authority & 1.227 & 0.169 & 0.917 & 1.642 \\
\hline \multicolumn{5}{|c|}{ Model 2: Discussed ACP with family/friends } \\
\hline Female & 1.579 & $<0.001$ & 1.271 & 1.952 \\
\hline Age (6 categories) & 1.396 & $<0.001$ & 1.289 & 1.511 \\
\hline Education (4 categories) & 0.985 & 0.828 & 0.863 & 1.125 \\
\hline Income (5 categories) & 1.125 & 0.026 & 1.014 & 1.247 \\
\hline Has 'kids' in household & 0.801 & 0.173 & 0.583 & 1.102 \\
\hline Not born in Canada & 0.939 & 0.699 & 0.687 & 1.286 \\
\hline Fraser Health Authority & 1.212 & 0.106 & 0.959 & 1.530 \\
\hline \multicolumn{5}{|c|}{ Model 3: Discussed ACP with healthcare provider } \\
\hline Female & 0.893 & 0.500 & 0.643 & 1.241 \\
\hline Age (6 categories) & 1.234 & $<0.001$ & 1.085 & 1.402 \\
\hline Education (4 categories) & 0.920 & 0.413 & 0.753 & 1.123 \\
\hline Income (5 categories) & 0.792 & 0.004 & 0.674 & 0.930 \\
\hline Has 'kids' in household & 0.359 & 0.008 & 0.169 & 0.765 \\
\hline Not born in Canada & 1.871 & 0.003 & 1.229 & 2.847 \\
\hline Fraser Health Authority & 1.204 & 0.305 & 0.845 & 1.716 \\
\hline \multicolumn{5}{|c|}{ Model 4: Has a written ACP plan } \\
\hline Female & 1.207 & 0.173 & 0.921 & 1.583 \\
\hline Age (6 categories) & 1.681 & $<0.001$ & 1.493 & 1.892 \\
\hline Education (4 categories) & 1.346 & 0.001 & 1.132 & 1.600 \\
\hline Income (5 categories) & 1.059 & 0.398 & 0.927 & 1.211 \\
\hline Has 'kids' in household & 1.004 & 0.987 & 0.612 & 1.646 \\
\hline Not born in Canada & 1.050 & 0.805 & 0.711 & 1.551 \\
\hline Fraser Health Authority & 0.504 & $<0.001$ & 0.370 & 0.687 \\
\hline \multicolumn{5}{|c|}{ Model 5: Has a designated decision maker } \\
\hline Female & 1.194 & 0.099 & 0.967 & 1.473 \\
\hline Age (6 categories) & 1.454 & $<0.001$ & 1.334 & 1.578 \\
\hline Education (4 categories) & 1.018 & 0.792 & 0.892 & 1.161 \\
\hline Income (5 categories) & 1.171 & 0.003 & 1.056 & 1.298 \\
\hline Has 'kids' in household & 1.036 & 0.831 & 0.749 & 1.434 \\
\hline Not born in Canada & 0.914 & 0.573 & 0.668 & 1.250 \\
\hline Fraser Health Authority & 0.756 & 0.018 & 0.599 & 0.954 \\
\hline \multicolumn{5}{|c|}{ Model 6: Aggregated ACP behaviour } \\
\hline Female & 1.37 & 0.001 & 1.140 & 1.646 \\
\hline Age (6 categories) & 1.478 & $<0.001$ & 1.376 & 1.587 \\
\hline Education (4 categories) & 1.072 & 0.236 & 0.956 & 1.202 \\
\hline Income (5 categories) & 1.117 & 0.018 & 1.019 & 1.224 \\
\hline Has 'kids' in household & 0.858 & 0.278 & 0.65 & 1.132 \\
\hline Not born in Canada & 1.019 & 0.895 & 0.773 & 1.342 \\
\hline Fraser Health Authority & 0.91 & 0.356 & 0.744 & 1.112 \\
\hline Cut 1 & 1.467 & - & 0.948 & 1.985 \\
\hline Cut 2 & 2.45 & - & 1.922 & 2.977 \\
\hline Cut 3 & 3.462 & - & 2.92 & 4.003 \\
\hline
\end{tabular}

Table 3 Continued

\begin{tabular}{lccll}
\hline & OR & $\mathrm{p}>|\mathrm{z}|$ & \multicolumn{2}{c}{$(95 \% \mathrm{Cl})$} \\
\hline Cut 4 & 4.721 & - & 4.154 & 5.287 \\
Cut 5 & 6.222 & - & 5.58 & 6.864 \\
\hline Logistic regression models of ACP outcomes on selected sociodemographic \\
variables Canadian Ipsos Reid sample ( $\mathrm{n}=1523)$, ORs and 95\% Cls. \\
Model 1 thru Model 5 use binary outcomes and Model 6 uses an ordinal \\
outcome. \\
Bold text indicates that the coefficient is significant. \\
ACP, advance care planning.
\end{tabular}

it comes to decisions about EOL, more respondents chose a substitute decision maker over writing an advance care plan. Silveira $e t ~ a l^{18}$ also reported higher rates of substitute decision makers instead of written living wills among a US sample of individuals, aged 60 years and older.

\section{Social determinants of ACP}

Research has shown that individuals more prone to discuss and complete advance directives are either older, Caucasian, have higher incomes or higher educational levels. ${ }^{12} \quad 13 \quad 19$ Other sociodemographic factors influencing ACP behaviour include gender, household composition, language proficiency and religion. $^{20} 21$ Our study confirms only some of these findings. In the present research, age was the only sociodemographic factor positively and significantly associated with all ACP outcomes. This result is not surprising since older Canadians are more likely than younger Canadians to face the diagnosis of a lifelimiting illness or become incapacitated. Women were more likely to discuss ACP with family and friends and to engage in more ACP practices. This result is in agreement with research that suggests that there is a difference in how women and men view ACP. ${ }^{22}$

Higher levels of education had a positive effect on the likelihood of knowing the term ACP, and having an ACP written down. This finding is expected since higher levels of education are associated with a lower preference for aggressive medical care at the EOL. ${ }^{23}{ }^{24}$ Higher-income respondents tended to discuss more ACP with family and friends, were more likely to have a designated decision maker, and adopted more ACP practices in general. These findings may be explained by the fact that higher-income individuals may be more prone to engage legal professionals as designated decision makers to manage their wealth.

The most surprising results concern respondents' discussions with HCPs. As expected, being older increased the likelihood of talking with HCPs, and living with children decreased the odds of talking with HCPs about EOL care. This finding supports current literature that suggests physicians are reluctant to initiate a conversation about ACP since they may not feel comfortable talking about death with their 
patients or afraid of taking away their hope. Having minor dependent children has been shown to increase the difficulty of such discussions for both dying patients and their HCPs. ${ }^{25-28}$ Besides feeling uncomfortable with conversations about EOL, HCPs have indicated fear of legal repercussions if the advance directive results in limiting care at the EOL. ${ }^{28}$ Moreover, research in the UK and the USA has indicated that physicians, more than other professionals, have significant reservations about the applicability and validity of ACP documents. ${ }^{29-32}$

The study found that higher income was associated with less communication with HCPs. This result differs from other reports that have suggested that higher socioeconomic status is associated with higher levels of information on EOL care. ${ }^{12}{ }^{20}$ Another surprising result was the higher rates of discussions with HCPs among individuals born outside Canada. Some research has contended that minority groups have lower rates of ACP completion and higher preference for the use of aggressive medical care while other authors have emphasised the fact that race and ethnicity are proxies for socioeconomic characteristics. ${ }^{12} 3334$ Do HCPs in Canada initiate conversations more frequently with patients born outside Canada because they assume these patients have less information on ACP? To answer such questions, more research is needed on the relationship between social factors and usage of ACP.

\section{A need for system-level ACP interventions in the FHA}

Comparisons of ACP usage in the FHA with the rest of Canada were inconclusive. Unadjusted results (table 2) suggested that there were significantly higher levels of ACP awareness and discussions with family and friends in the FHA. However, once these results were adjusted for the demographic characteristics of the FHA, they were no longer significant. Moreover, FHA residents were less likely to have a written ACP or a substitute decision maker. These findings may be explained by the fact that while Fraser Health had engaged professionals and the public around ACP, legislation supporting ACP practices was only declared in the fall of 2011. Unlike many other Canadian provinces, the public in $\mathrm{BC}$ had no prior standardised access to government information about how to develop an ACP or how to approach a HCP around healthcare decision making at the EOL. Comparisons of ACP prevalence in the FHA with the rest of $\mathrm{BC}$ showed no significant differences. However, the relatively low number of frequencies that some of the cells register may explain the lack of significance found in the statistical tests.

The present study represents a first step in analysing the effectiveness of the ACP initiatives in the FHA. However, a follow-up study that replicates the ACP questions in the FHA population after the introduction of the 2011 ACP legislation, is needed to evaluate the results of the FHA's ACP intervention when supported by legal tools.

\section{Policy implications}

Patients with different sociodemographic characteristics engage in the various dimensions of ACP differently. From a policy perspective, this finding is important because it highlights the need for focused interventions according to the different components of ACP that one is trying to promote. Moreover, by emphasising that different groups of population behave distinctively towards ACP, this study also stresses the need for interventions that target specific population demographics. In what follows, we highlight four main implications for policy makers regarding ACP:

- Older Canadians report higher levels of engagement in ACP behaviour. Promoting EOL discussions in the broader population may encourage younger individuals to manage EOL issues with their own aging parents and relatives. From a health perspective, there is the need to promote the concept of ACP as healthcare information that concerns everyone.

- Our sample exhibited low levels of ACP discussions with HCPs. This finding stresses the need to develop focused activities to engage HCPs in ACP with patients and families. Educational programmes should prepare HCPs on strategies to communicate with their patients about death and ACP, and also include tools that help HCPs communicate with culturally and demographically diverse populations.

- Our results point to the fact that women are more likely to discuss their wishes with family and friends. The fact that women are most often caregivers and initiators of caregiving in Canada, ${ }^{35}$ provides an important opportunity for ACP engagement and facilitation.

- Finally, results from the comparative analysis between the FHA and the rest of Canada suggest that changes in the number of individuals using ACP appear to be unaffected unless there are legal and regulatory supports for ACP engagement.

\section{Limitations}

A main limitation of this study is that it does not use a random sample of the Canadian population, and therefore the findings of this study may not be generalisable to the broader Canadian population. However, to the best of our knowledge, this is the first study in Canada to examine ACP-specific behaviour using a relatively large sample of the Canadian population which closely resembles the Canadian population characteristics on age, gender, region and education. Another limitation of the present study is that the data gathered by this opinion poll survey does not provide in-depth and detailed insights about ACP practices and behaviours. Additionally, the ACP outcomes used in this study do not offer information about the type of advance care plan respondents have (eg, advance directive, workbook, etc) and the degree of formality in designating a decision maker.

\section{CONCLUSIONS}

This study presents an analytical framework of ACP, divided into three main dimensions: awareness, 
communication and decision making. The main findings of the study indicate that although only a small group of Canadians is aware of the formal term 'ACP', a higher percentage of Canadians actually used ACP in their lives, through either having discussions or making decisions about EOL care. Second, the findings point to the fact that Canadians tend to speak more with their family and friends about ACP matters than with their own doctors or other HCPs. Third, when it comes to decision making about EOL matters, more respondents have a designated decision maker, than a written advance care plan. Our study shows that specific social and demographic characteristics are significantly and differently associated with the three dimensions of ACP. Finally, the study suggests that regulatory frames need to be in place in order to provide optimal support to ACP interventions.

\section{Author affiliations \\ ${ }^{1}$ Department of Medicine, Queen's University, \\ Kingston, Ontario, Canada \\ ${ }^{2}$ Canadian Hospice Palliative Care Association, Ottawa, Ontario, Canada \\ ${ }^{3}$ Fraser Health Authority, Surrey, British Columbia, Canada \\ ${ }^{4}$ Division of Palliative Care, Department of Medicine UBC, Surrey, British Columbia, Canada \\ ${ }^{5}$ Clinical Evaluation Research Unit, Kingston General \\ Hospital, Kingston, Ontario \\ ${ }^{6}$ Department of Community Health and \\ Epidemiology, Queen's University, Kingston, Ontario, Canada}

Acknowledgements The authors wish to thank Andrew Day (CERU-KGH) for his help in statistical advising, Jessica Simon, Kristine Votova and Robert Fowler, members of the Canadian Researchers at the End of Life Network (CARENET), and anonymous reviewers for their review of this manuscript. We also wish to thank David Scowcroft for his help in providing access to the Ipsos Reid (Canada) opinion poll.

Contributors AT contributed to conception and design of the study; analysis and interpretation of data; drafting of the manuscript; and statistical analysis. DH contributed to conception and design of the study; analysis and interpretation of data; drafting of the manuscript; conception and design of survey methodology and commissioning of survey data. LH, CT, DB and $\mathrm{SB}$ contributed to critical revision of the manuscript; conception and design of survey methodology and commissioning of survey data. All authors approved the final version of the manuscript.

Funding This study used a dataset commissioned by CARENET (Canadian Researchers at the End of Life Network, http://www. thecarenet.ca), the Fraser Health Authority (http://www. fraserhealth.ca), the Canadian Hospice and Palliative Care Association (http://chpca.net), and the Speak Up Campaign and conducted by Ipsos Reid.

Competing interests None.

Ethics approval The present research received ethical approval from the Health Sciences Research Ethics Board of Queen's University in Kingston, Ontario (Canada).

Provenance and peer review Not commissioned; externally peer reviewed.

Open access This is an Open Access article distributed in accordance with the Creative Commons Attribution Non
Commercial (CC BY-NC 3.0) license, which permits others to distribute, remix, adapt, build upon this work non-

commercially, and license their derivative works on different terms, provided the original work is properly cited and the use is non-commercial. See: http://creativecommons.org/licenses/by$\mathrm{nc} / 3.0 /$

\section{REFERENCES}

1 Heyland DK, Barwich D, Pichora D, et al. Failure to engage hospitalized elderly patients and their families in advance care planning. JAMA Intern Med 2013;173:778-87.

2 Heyland DK, Pichora D, Dodek P, et al. The development and validation of a questionnaire to audit advance care planning. J Palliat Care Med 2012;2:119.

3 Advance Care Planning in Canada: National Framework and Implementation Task Group. Advance care planning in Canada: a national framework for consultation. Canadian Hospices Palliative Care Association, 2010. http://akeresourcecentre.org/ files/ACP/ACP_National\%20Framework_Full.pdf (accessed 13 Aug 2012).

4 Houttekier D, Cohen J, Cools F, et al. Advance care planning for end-of-life care (Protocol). Cochrane Database Syst Rev 2012;2:CD009618.

5 Brown P, Enns B, Wasylenko E, et al. Implementation Guide to Advance Care Planning in Canada: A Case Study of Two Health Authorities. Calgary Health Region, Fraser Health Authority, Health Canada, 2008. http://www.hc-sc.gc.ca/hcs-sss/pubs/palliat/ 2008-acp-guide-pps/index-eng.php (accessed 12 Aug 2012).

6 Thelen M. End of life decision making in the intensive care. Crit Care Nurse 2005;25:28-37.

7 Tilden VP, Tolle SW, Nelson CA, et al. Family decision-making to withdraw life sustaining treatments from hospitalized patients. Nurs Res 2001;50:105-15.

8 Tilden VP, Tolle SW, Nelson CA, et al. Family decision making in foregoing life extending treatments. J Fam Nurs 1999;5:426-42.

9 Singer PA, Choudhry S, Armstrong J, et al. Public opinion regarding end-of-life decisions: influence of prognosis, practice and process. Soc Sci Med 1995;41:1517-21.

10 Ipsos Reid. Hospice Palliative Care Study. Final report. Ipsos Reid, 2004.

11 Pew Research Center. Strong public support for right to die. More Americans discussing — and planning —end-of-life treatment. Pew Research Center for the People and the Press, 2006. http://www.people-press.org/2006/01/05/ strong-public-support-for-right-to-die/\#summary-of-findings (accessed 31 Aug 2012).

12 Wilkinson A, Wenger N, Shugarman LR. Literature Review on Advance Directives. Prepared for Office of Disability, Aging and Long-Term Care Policy, U.S. Department of Health and Human Services, 2007. http://aspe.hhs.gov/daltcp/reports/2007/ advdirlr.htm (accessed 22 Aug 2012).

13 Con A. Cross-cultural considerations in promoting advance care planning in Canada. Secretariat on Palliative and End-of-Life Care, Primary and Continuing Health Care Division of the Health Care Policy Directorate, Health Canada, 2007. http:// www.bccancer.bc.ca/NR/rdonlyres/ E17D408A-C0DB-40FA-9682-9DD914BB771F/28582/ COLOUR030408_Con.pdf (accessed Aug 2012).

14 Hammes BJ, Rooney BL, Gundrum JD. A comparative, retrospective, observational study of the prevalence, availability, and specificity of advance care plans in a County that implemented an advance care planning microsystem. $J \mathrm{Am}$ Geriatr Soc 2010;58:1249-55. 
15 Ashby M, Wakefield M. Attitudes to some aspects of death and dying, living wills and substituted health care decision-making in South Australia: public opinion survey for a parliamentary select committee. Palliat Med 1993;7:272-82.

16 Ipsos Healthcare. Advance Care Planning. Canadian Sample. Study commissioned by CARENET, Fraser Health Authority, the Canadian Hospice Palliative Care Association and the Speak Up Campaign, 2012.

17 Ipsos Healthcare. Advance Care Planning. Fraser Health Comparison. Study commissioned by CARENET, Fraser Health Authority, the Canadian Hospice Palliative Care Association and the Speak Up Campaign, 2012.

18 Silveira MJ, Kim SY, Langa KM. Advance directives and outcomes of surrogate decision making before death. $\mathrm{N} \mathrm{Engl} \mathrm{J}$ Med 2010;362:1211-18.

19 Troyer J, McAuley W. Environmental contexts of ultimate decisions: why white nursing home residents are twice as likely as African American residents to have an advance directive. J Gerontol 2006;61B:S194-202.

20 Carr D. Racial and ethnic differences in advance care planning: identifying subgroup patterns and obstacles. J Aging Health 2012;24:923-47.

21 California Healthcare Foundation. Final Chapter: Californians' attitudes and experiences with death and dying. California Healthcare Foundation, 2012. http://www.chcf.org/ /media/ MEDIA\%20LIBRARY\%20Files/PDF/F/PDF\%

20FinalChapterDeathDying.pdf (accessed Aug 2012).

22 Perkins HS, Cortez JD, Hazuda HP. Advance care planning: does patient gender make a difference? Am J Med Sci 2004;327:25-32.

23 Volandes AE, Ariza M, Abbo ED, et al. Overcoming educational barriers for advance care planning in latinos with video images. J Palliat Med 2008;11:700-6.

24 Volandes AE, Paasche-Orlow M, Gillick MR, et al. Health literacy not race predicts end-of-life care preferences. J Palliat Med 2008;11:754-62.

25 Hudson T. Advance directives: still problematic for providers. Hosp Health Netw 1994;68:46-50.
26 Royal College of Physicians, National Council for Palliative Care, British Society of Rehabilitation Medicine, British Geriatrics Society, Alzheimer's Society, Royal College of Nursing, Royal College of Psychiatrists, Help the Aged, Royal College of General Practitioners. Advance care planning. Concise Guidance to Good Practice series, No 12. London: RCP, 2009. http://www.rcplondon.ac.uk/pubs/contents/9c95f6ea-c57e-4db8-bd98fc12ba31c8fe.pdf (accessed 3 Jan 2013).

27 Sahm S, Will R, Hommel G. Attitudes towards and barriers to writing advance directives amongst cancer patients, healthy controls and medical staff. J Med Ethics 2005;31:437-40.

28 Mack JW, Smith TJ. Reasons why physicians do not have discussions about poor prognosis, why it matters, and what can be improved. J Clin Oncol 2012;30:2715-7.

29 Shore AD, Rubin HR, Haisfield ME, et al. Health care providers' and cancer patients' preferences regarding disclosure of information about advance directives. J Psychosoc Oncol 1994;11:39-53.

30 Haisfield ME, McGuire DB, Krumm S, et al. Patients' and healthcare providers' opinions regarding advance directives. Oncol Nurs Forum 1994;21:1179-87.

31 Neuman K, Wade L. Advance directives: the experience of health care professionals across the continuum of care. Soc Work Health Care 1999;28:39-54.

32 Fried TR, Rosenberg RR, Lipsitz LA. Older community-dwelling adults' attitudes toward and practices of health promotion and advance planning activities. J Am Geratr Soc 1995;43:645-49.

33 Perkins HS, Geppert CM, Gonzales A, et al. Cross-cultural similarities and differences in attitudes about advance care planning. J Gen Intern Med 2002;17:48-57.

34 Kwak J, Haley WE. Current research findings on end-of-life decision making among racially or ethnically diverse groups. Gerontologist 2005;45:634-41.

35 Cranswick K. Caring for an aging society. Housing, Family and Social Statistics Division, Statistics Canada, N/D. http:/www. statcan.gc.ca/pub/89-582-x/index-eng.htm (accessed 20 Nov 2012). 